\title{
AMAZONIA BRASILEÑA: LA DESARTICULACION DE LOS PAISAJES CULTURALES ${ }^{1}$
}

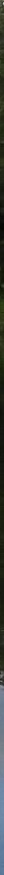

José Manuel Mateo Rodriguez

Prof. Pós-doutor e Titular Facultad de Geografia Universi-

dad de La Habana / Prof. Visitante da Universidade Estadual Paulista (UNESP/Rio Claro)

email: mateopaisajescuba@gmail.com

RESUMO

O presente trabalho foi desenvolvido a partir da análise teórica e empírica da região amazônica. O objetivo desse trabalho é discutir as diversas paisagens, levando a descrição e caracterização dos lugares e conceituá-los partindo de um viés geográfico que mescla a vivencia e experiência intelectual e acadêmica. Neste sentido, o trabalho traz uma abordagem sob o olhar do conceito de Paisagem desenvolvido pela Ciência Geografia que se somatizam com reflexões de diversos ambientes naturais e culturais.

Palavras - chave: Geografia. Paisagem. Amazônia.

\section{RESUMEN}

El presente trabajo fue desarrollado a partir del análisis teórico y empírica de la región amazónica. El objetivo de este trabajo es discutir los diversos paisajes, llevando la descripción y caracterización de los lugares y conceptuarlos partiendo de un sesgo geográfico que mezcla la vivencia y experiencia intelectual y académica. En este sentido, el trabajo trae un enfoque bajo la mirada del concepto de Paisaje desarrollado por la Ciencia Geografia que se somatizan con reflexiones de diversos ambientes naturales y culturales.

Palabras clave: Geografia. Paisaje. Amazonas.

1

Este articulo, ha sido el resultado de las observaciones realizadas en los trabajos de campo realizados en diversos estados de la Amazonia Brasileña, y en el Estado de Acre, con el apoyo de la CAPES (entidad de apoyo del Ministerio de educación De Brasil) y el Instituto de Medio Ambiente de Acre (IMAC)., entre los anos de 1994 y 2001. El autor quiere agradecer en particular al Dr. Profesor Edson Vicente da Silva (Cacau), de la Universidade Federal do Ceara, y al Dr. Jarion do Nascimento de la Universidade Federal de Acre, por su apoyo y colaboración. 


\section{INTRODUCCIÓN}

La Amazonia es una región única del mundo. En la Amazonia los números que caracterizan sus dimensiones son inmensos. Pero, más que su grandeza, su papel se revela como pulmón del globo terráqueo. Durante anos, una no muy significativa población de nativos y de poblaciones amazónicas ha formado cultura, creando espacios y buscando formas de adaptación con ese medio natural agreste. El paisaje, como telón de fondo, sirvió de sustento para la formación de las culturas amazónicas, como elemento único de la relación naturaleza- sociedad. El reto hoy es la búsqueda de un nuevo paradigma de desarrollo, que logre, en la medida de lo posible, corregir el camino errático de la formación de un producto cultural estandarizado y homogenizado en lugar de la riqueza paisajística de las culturas amazónicas. La implantación de la modernidad, primero traída como consecuencia de la Revolución Industrial, y ya a mediados del siglo XX, como brújula del desarrollo impuesto por las elites políticas y económicas, ha dado lugar a la desintegración deltejido espacialypaisajístico, hilvanado por siglos por las culturas locales. La reconstrucción del proceso de desarrollo, no es posible si no se adhiere a un esfuerzo real por reconstituir el fondo paisajístico, y la intricada red de lugares que forman la base contextual de la región amazónica. A analizar como se han desarticulado los paisajes de la Amazonia, como fundamento cultural de su población, y a vislumbrar los caminos para su reconstrucción, esta dedicado este articulo.

\section{DISCUSIÓN}

\section{PAISAJE, LUGAR Y TERRITORIO: SOSTENEDORES DE LA CULTURA}

En el proceso de transformación de la superficie terrestre, de su construcción y reconstrucción por la acción colectiva de los seres humanos, son creados y recreados modos de relación de la sociedad con el medio natural y social, y con los otros seres humanos, y se va produciendo cultura. Esto significa que la apropiación, ocupación y transformación del espacio geográfico, es un proceso cultural, porque se crean bienes materiales, valores, modos de hacer, de pensar, de percibir el mundo, todo lo cual constituye el patrimonio cultural construido por la humanidad a lo largo de la historia.

El paisaje es la fisonomía, la morfología o la expresión formal del espacio, de los territorios, y tiene como función soportar una identidad, y servir de base para estimular la cohesión hacia adentro de las sociedades, y rechazar la influencia de los desarticuladores externos. El paisaje, es así, el fundamento de la formación de las identidades. El paisaje integra el lenguaje científico con el emocional, permitiendo el reforzamiento mutuo entre el saber geográfico y la identidad cultural (MATEO, 2003).

La realidad geográfica se convierte así en el escenario contextual de los procesos políticos, económicos y sociales. Al ser el territorio, el contenedor político por excelencia, y el espacio de las prácticas territoriales del Estado, constituye así el escenario de las acciones territoriales. Estas, constituyen la puesta en ejecución de la división y ordenación de las diferentes entidades espaciales. El producto de las prácticas espaciales, son las diversas formas de organización que el poder y las sociedades ponen en marcha en el control, dominio y gestión del propio territorio. Las prácticas y procesos territoriales, delimitan ámbitos de intervención, espacios de competencia y responsabilidad. No hay poder sin territorio.

El paisaje es un grupo de formas, de los objetos y elementos que definen a un espacio 
geográfico. Es dentro de sus límites, que se lleva a cabo, las interrelaciones sociales, económicas y culturales con el medio natural, y con las transformaciones que este ha experimentado. Es por lo tanto, parte del ambiente de los seres humanos. En el paisaje existen formas y estructuras, que reflejan el dominio, el sometimiento, el poder y la religiosidad., la funcionalidad y su uso practico por diversas generaciones de seres humanos.. Todas las edificaciones humanas transforman el paisaje natural en un paisaje antropizado. Este ultimo refleja los estilos y las ideologías que han prevalecido en una época, pero también proyectan la valoración económica del espacio y sus elementos arquitectónicos agregados. Componentes tales como la altura, la distancia entre los objetos y los espacios ocupados, los materiales utilizados, los detalles decorativos, el espacio interior y la ecología del entorno ayudan a definir el patrón y los valores del orden socio - económico imperante en su construcción (SEGUINOT, op. cit.).

Por su valor en la formación de la identidad, el paisaje es el fundamento de la personalidad colectiva, y constituye de por si un elemento básico en la memoria territorial e histórica de los pueblos. Los paisajes tienen mucho que contar y mucho que enseñar a quienes saben y quieren leerlos. Revelar los contenidos del patrimonio natural y cultural que está presente en los paisajes, a través de una lectura experta, constituye un ejercicio de cultura geográfica, ambiental y territorial.

El paisaje se define a partir de la cultura de un grupo, comunidad o pueblo. Los paisajes son ambientes simbólicos, creados por la acción humana para conferir significado y forma a la Naturaleza y al ambiente, a partir de un conjunto de valores y creencias. Los paisajes poseen significados simbólicos porque son el producto de la apropiación y la transformación del medio ambiente por el hombre. El paisaje le imprime al espacio sus convicciones, valores y formas de organización social. Culturalmente, se produce una iconografía con su propia identidad. El paisaje al ser matizado de simbolismo., refleja la apreciación simbólica de una cultura y posee elementos que proyectan las contradicciones sociales de la apropiación del territorio (SEGUINOT, 1996).

En el fomento, conservación y formación de la identidad cultural y territorial y en la creación de un imaginario colectivo, el paisaje, al estar cargado de geo símbolos, de afectividad, de normas y de limites sagrados representa no sólo un concepto, sino un instrumento para operacionalizar y definir intervenciones y acciones concretas. De tal manera, el paisaje es fundamental para la cultura porque:

- Es la marca de la cultura al ser la base en la cual se sustenta la misma, expresando las características de las civilizaciones

Es la matriz de la cultura, al ser el soporte de la identidad, participando activamente en su construcción y formación.

- $\quad$ Es el fundamento de las imágenes, las cuales son a su vez, la base de la formación de las identidades.

- $\quad$ Es el soporte de las relaciones afectivas de los seres humanos con su entorno, y fundamento en la formación del concepto de lugar y de territorialidad.

La noción de lugar, se apoya en la conceptualizacion de género de las categorías de paisaje y territorio (FERREIRA, 2002). El lugar es en esencia una producción humana, ya que en el mismo se reproduce la relación entre el espacio y la sociedad, lo que significa la creación y el establecimiento de una identidad entre la comunidad y el lugar. Esa identidad se da por medio de la apropiación del lugar para la vida, cumpliendo el mismo una función existencial. En el lugar, el habitante establece sus relaciones sociales, las relaciones de la sociedad con la propia sociedad, y las relaciones de la Sociedad con 
la Naturaleza (BARBOSA, 2001).

Los lugares son centros a los cuales atribuimos valor, donde se llevan a cabo las necesidades biológicas de comida, agua, descanso, y procreación. Por eso los lugares son diferentes unos de los otros. La organización de la actividad vital de los seres humanos, que genera prácticas sociales, tiene como resultado un diferente arreglo y un patrón distintivo a cada lugar. Es como si el lugar tuviese, de forma inconfundible, su propia fisonomía. El lugar es el centro profundo de la existencia humana. Pero el lugar, es también una construcción social y debe ser comprendido sobre la base de la relación entre el espacio - tiempo y el ambiente. El patrón geográfico de los lugares, por otra parte, no es pre determinado, siendo función de la competencia espacial entre los lugares, lo cual generara lugares vencedores y lugares perdedores.

El lugar seria entonces definido por un conjunto de artefactos geoecológicos materiales y la red de relaciones sociales, como foco de deseos y creencias, de actividades discursivas ligadas a significados simbólicos y como producto del poder político y económico institucionalizado. La construcción del espacio estaría, de este modo, relacionada a todos estos procedimientos capturados en el flujo común del proceso social (HARVEY, 1996, p. 316, citado por FERREIRA, 2002). Del mismo modo, los lugares que expresan valores de la comunidad que en ellos viven.

De tal manera, la noción de paisaje, es una categoría de género, en tanto que la de lugar, expresa a los paisajes a nivel local, de la misma manera que la noción de región tiene el carácter de un taxón mas elevado y complicado, que expresa en si la interrelación entre lugares.

\section{EL PROCESO DE DESARTICULACI- ÓN DE LOS PAISAJES, TERRITO- RIOS Y LUGARES}

La consolidación del período científico - técnico contemporáneo o modernidad ha dado lugar a una organización espacial completamente nueva, lo que se ha dado en llamar "medio científico - técnico informacional" (M. SANTOS, 1985, 1994, 1996). Este nuevo tipo de medio, que se expande de manera cada vez mayor, es el resultado de la construcción y reconstrucción permanente del espacio geográfico con contenidos cada vez mayores de ciencia, tecnología e información. Ello da lugar, a una nueva cara del espacio, que es la base material para la globalización, y cuya expansión se da con el acrecentamiento de objetos artificiales sobre los territorios basados en una uniformidad tecnológica.

Así, este nuevo tipo de medio, es la consecuencia espacial del proceso de globalización. En este período de la modernidad se crean nuevas formas de espacialización. Un rasgo característico de la crisis ambiental contemporánea, es que se da en íntima relación con la reestructuración espacial. De tal forma, se desorganizan las formas de producción y organización social pre - existentes, creándose nuevas desigualdades. Se produce al mismo tiempo, una fragmentación y especialización regional a escala internacional, que conduce a convertir a cada lugar en diferente, porque cada lugar asume los procesos de cambios de manera diferenciada. O sea, la propia globalización acaba en producir fragmentación, porque a medida que los lugares se globalizan se hacen cada vez más singulares.

Este nuevo ciclo civilizatorio conduce a que las relaciones entre la sociedad y la naturaleza, pasa por importantes transformaciones. Tanto la naturaleza, como la vida de los seres humanos, se hace cada vez más de forma artificial. Así, un primer efecto del desarrollo moderno, es el impacto sobre la cultura. La sumisión de las culturas a un propósito único de acumulación está significando la pérdida progresiva de la 
heterogeneidad cultural. La cultura ha ido perdiendo así su significado de modelo adaptativo a las circunstancias locales o regionales, para convertirse en un ropaje unificado y en un sistema articulado de explotación del medio natural. A instrumentos similares responden así, símbolos idénticos (ANGEL MAYA, 1995).

La Tierra va siendo ahora dividida, no por la diversidad cultural, sino por el mismo sistema de acumulación, que aumenta las desigualdades y la brecha entre ricos y pobres. El inmenso desarrollo de la calidad de vida en los países ricos, no se ha logrado sino en función de la explotación de los recursos de los países pobres y en la subordinación de sus culturas.

Rasgo específico de este nuevo medio es la aceleración de la urbanización, y el crecimiento numérico y espacial de las ciudades. Las explotaciones agrícolas se hace cada vez más integrada al circuito de la economía urbana. Ello conduce a una mayor integración interna en el ámbito regional y nacional, a una mayor división social y territorial del trabajo, aumentando las interrelaciones entre el campo y la ciudad, acrecentándose el papel de las ciudades en la organización espacial, creándose sistemas técnicos que son indiferentes a las propiedades de los sistemas naturales.

La crisis ambiental, se deriva en gran parte de una falta de perspectiva espacial y territorial. La drástica desterritorialización propia de la modernidad, que conllevan las propuestas de desarrollo económico a ultranza se edifica, casi siempre, a costa de la miseria y ruina de los territorios y las sociedades, que son monumentos de riqueza ficticia y efimera que conducen a la desorganización traumática del entorno humano a diversas escalas.

El actualmente prevaleciente modelo consumista y economicista, da lugar a comportamientos de corte estandarizado que lleva el germen del desarraigo de cada sociedad de su espacio geográfico. En esos casos, la relación naturaleza - sociedad, es sustituida por relaciones hombre - máquina, hombre - artefacto, en la que los flujos de información, económicos y culturales, adolecen de referencia espacial o falta de localización.

La tendencia en dirección a una mayor interdependencia global esta llevando al colapso a todas las identidades culturales, a la multiplicidad de estilos, y al énfasis en lo efimero, en lo no permanente, en las semejanzas y en la homogenización cultural. Colocadas por encima de la cultura nacional, las identificaciones globales comienzan a predominar y algunas veces a liquidar a las identidades nacionales, regionales y locales En eso, las imágenes circulan en el planeta de forma avasalladora, las identidades comienzan a perder la autenticidad y pasan a ser globales.

Todo esto conduce a la deslugarizacion como un fenómeno característico de la desarticulación de los paisajes. Si un lugar se puede definir como “identitario ", relacional e histórico, un espacio que no se puede definir como "identitario " ni como relacional, ni como histórico, se define como no lugar .Los no lugares son espacio icónicos. Un espacio icónico reproduce la apariencia de un mundo real .Son así rasgos característicos de la deslugarizacion:

La virtual ausencia de adaptación a las condiciones locales

- La cada vez menos posible creación autentica de lugares;

- La formación cada vez mas dificil de un sentido profundo de lugar. La ausencia del sentido del lugar, en la no preocupación con las expresiones simbólicas de los lugares

- La disminución del numero de lugares significativos y de paisajes diferenciados

La uniformizacion de los productos y los lugares que pasan a ser creados para personas con necesidades y gustos supuestamente uniformes de acuerdo a los 
valores de masa, formulados por la industria, el gobierno y los diseñadores.

- El crecimiento continuo de las experiencias inauténticas

\section{LOS PAISAJES DE LA AMAZONIA}

En sus rasgos generales, la Amazonia constituye una amplia llanura plana que se encuentra bajo un clima ecuatorial húmedo, en la que predomina la cobertura de las selvas altas o bosque pluvial, sobre suelos ferralítico rojo amarillentos. La Amazonia es una enorme cuenca geográfica, que se extiende desde la del Brasil, abarcando otros 7 países. La cuenca amazónica se formo hace mas de 420 millones de anos, en la era paleozoica. En esa época el río fluía al oeste. En el Terciario, la separación de los continentes y el surgimiento de los Andes, invirtieron los cursos de agua para el este.

Partiendo de esa caracterización general, se puede distinguir los siguientes rasgos de los paisajes naturales de la Amazonia:

- Es característica una alta diversidad de los paisajes naturales: abarca desde paisajes sub húmedos hasta super húmedos; desde llanuras litorales y aluviales, hasta depresiones, llanuras altas onduladas y planaltos, desde el nivel del mar hasta los 3000 metros de altitud, desde manglares, y pantanos hasta sabanas (MATEO et al, 2004).

Predominio de los paisajes fluviales con bosque ombrofilo .Este bosque contiene la mayor diversidad biológica de todos los biomas terrestres. Ya fue aquí registrada una diversidad de 300 especies distintas de árboles en $2 \mathrm{~km} 2$. Los bosques son responsables del $50 \%$ de la humedad local En el mosaico de los bosques de la Amazonia hay una gran Cordillera Andina y avanza por todo el norte

diversidad de formaciones vegetales que pueden ser agrupadas en tres tipos básicos: los bosques de tierra firme, los bosques de varzea y los igarapes. El desarrollo de esos tipos depende del régimen de inundación de los ríos. Así el dominio amazónico comprende las llanuras inundadles del Amazonas y sus afluentes con bosques de tierra firme, varzeas y la mata de igapo; las mesetas o tabuleiros con vertientes semi mamelonares, los cerros o morros bajos en forma de media naranja (amamelonados) en las áreas donde afloran las rocas cristalinas; y las terrazas con cascajos y cortezas duras de laterita.

- La cuenca amazónica esta formada por una gran extensión de tierras de bajas latitudes que contienen una completa red de canales, lagos y lagunas que drenan desde los Andes, las Guyanas y el Brasil Central. Esa trama de aguas es responsable por el $20 \%$ de todo el agua dulce que llega a los océanos (BUENO CONTI Y FULAN, 2000).

- Condiciones naturales peculiares: suelos ácidos, ricos en elementos tóxicos; rápida e intensa circulación de materia, intenso calor y humedad. Todo ello conduce a una marcada inestabilidad, fragilidad y baja resiliencia de los espacios naturales.

- Medio ecológico extremo: predominio de la baja fertilidad agrícola, y del proceso de latosolizacion; Dificiles condiciones de accesibilidad, y comunicabilidad Todo ello determina la existencia de condiciones extremadamente complejas de adaptabilidad humana al medio natural.

- Los bosques amazónicos presentan un funcionamiento auto regulado. Para formar la densa biomasa que poseen, esos bosques necesitan de una alta tasa de fotosíntesis y de disponibilidad de nutrientes, .Ellos no viven de los nutrientes del suelo que son de baja fertilidad. El bosque tiene un sistema de reciclaje que captura los nutrientes a través de una estrategia de fijación biológica promovida $1 \quad$ El análisis de los paisajes naturales, y de las transformaciones de los espacios presentados en este articulo, se han basado en gran parte en la caracterización realizada en el texto Geografia do Brasil, coordinado por Juranyr Sanches Roiss, y editado en el ano 200 por la Universidad de Sao Paulo. 
por bacterias del suelo. El manto de detritos (hojas, tronos caídos, animales muertos) lleva a cabo ese reciclaje.

Los bosques húmedos se sustentan sobre suelos de los grupos latosolico y podsolico. Los mismos se caracterizan por una baja disponibilidad de nutrientes minerales. De tal manera, el 58 \% del nitrógeno circulante en el sistema esta en las plantas y no en los suelos. La productividad de este tipo de bosques esta en la biomasa, transfiriéndose poco material para los suelos. La renovación del humus es extremadamente rápida, lo que significa que los detritos no se acumulan en los suelos.

La implantación de la agricultura y los pastos en tales condiciones destruyen el sistema de almacenamiento y reciclaje de nutrientes, y por consecuencias conducen a la perdida completa de la fertilidad. Al no existir vegetación arbórea, los nutrientes son lavados e intemperizados rápidamente debido al aumento de la temperatura en la superficie.

El gran daño ambiental consecuencia de la deforestación reside, justamente en la perdida del sistema de reciclaje y el rápido empobrecimiento de los suelos, que convierte a muchas áreas en verdaderos "desiertos rojos".

La Gran Región Amazónica, que comprende así la cuenca y la Depresión Teutónica de la Amazonas, puede ser divida en tres grandes regiones: Amazonia Occidental, Amazonia Oriental y el Planalto Amazónico.

La Amazonia Occidental, es un ejemplo clásico del paisaje ecuatorial húmedo. Aquí se extienden los "ríos brancos", que corren lentamente y tienen múltiples meandros, caracterizados por el predominio de partículas amarillentas en suspensión. Aquí se difunden los igarapes, que se encuentra en el plano de inundación bajo. En el plano de inundación alto que se inunda solo por periodos cortos de grandes inundaciones, se forma la varzea alta. La tierra firme, ocupa partes ligeramente onduladas, que no se inundan.

La Amazonia Oriental. Aquí el clima consiste en una variante sub ecuatorial húmeda y semi húmeda, con un periodo seco, teniendo sus bosques especies caducifolias. Frecuentemente se forman mesas, de rocas cuarcititas. Los ríos que corren ese basamento toman el nombre de "ríos negros", y son formados por depósitos orgánicos mayormente con pocos nutrientes.. Aquí se extiende el amplio delta del Amazonas, alcanzando allí el río un ancho de hasta 80 kilómetros., con una amplia cobertura de manglares.

El Planalto Amazónico: es un área formada por sedimentos arcillosos, con terrenos de altitudes entre 150 a 200 metros de altura de la Amazonia. Aquí predominan las depresiones sub ecuatoriales y planaltos residuales húmedos y hasta semi secas, en las cuales a menudo se levantan colinas de paredes escarpadas, y vertientes que alcanzan hasta los 3000 metros de altitud, en el Pico de la Neblina. Limitan por el norte y por el sur, los terrenos mas antiguos que forman los escudos cristalinos.

\section{LA ADAPTACIÓN DE LAS CULTURAS Y SOCIEDADES INDÍGENAS A LOS PAISAJES NATURALES DE LA AMAZONIA}

Las poblaciones tradicionales, formadas principalmente por indígenas, seringueiros (colectores de latex), y ribereños, lograron adaptarse a las condiciones naturales extremas de la cuenca. En general el sistema agrícola se implantaba mediante pequeños módulos dentro del bosque y con rotación de tierras. La técnica conocida con el nombre indígena de "coivara", era una especie de consorcio entre especies, que permiten un reciclaje de materias orgánicas y el descanso de tierras. Ello favorece la sucesión secundaria, permitiendo la reconstrucción de 
los bosques y de los ciclos de nutrientes.

Los indígenas eran en gran parte semi nómadas, al hacer grandes recorridos, a través básicamente de los ríos, con el propósito de cazar y pescar. Los poblados pequeños, estaban formados por materiales locales, con casas de madera y paja, en muchos casos colgados sobe palafitas. Esta red de asentamientos, se completaba con lugares sagrados (montes, lagos, ríos, colinas) que constituían el entorno simbólico y existencial de las poblaciones indígenas.

De tal modo, las características de las culturas indígenas y de las poblaciones tradicionales, en su adaptación al medio natural agreste de la Amazonia fueron las siguientes:

- Adaptación total al medio natural: llevada a cabo bajo condiciones de baja intensidad de explotación, el uso de recursos locales, y el predominio del bosque como fondo natural.

Fragmentación espacial, topofilia significativa, formada por una intrincada red de lugares, con difícil comunicación entre si, fundamentalmente a través de arterias y vías de conectividad fluvial, lo que determina una débil integración espacial entre la red de lugares, solo usada efectivamente en las actividades semi nómadas de caza y pesca.

- Intensa relación topofilica entre las poblaciones con su medio: las poblaciones tradicionales conocen y dominan el espacio $y$ el paisaje en el cual y del cual viven, y establecen una relación afectiva y sentimental de carácter existencial con esos lugares.

- $\quad$ Aislamiento regional y local, : la región como un todo, y su red de lugares estaban fuertemente aisladas, debido a las dificultades de acceso y comunicación.

- $\quad$ Significativo papel de los ríos y del agua, en la estructura simbólica del paisaje

\section{PROCESOS DE DESARTICULACIÓN ESPACIAL EN LA CUENCA DEL}

\section{AMAZONAS}

El paso a la modernidad, y la tentativa de las poblaciones europeas de ampliar su cultura a todo el globo terráqueo, y en particular a la construcción y colonización de los nuevos territorios ha estado acompañada por los siguientes rasgos:

Nueva organización espacial de la modernidad: que se manifiesta en la consolidación del medio científico - técnico - informacional que ha sustituido al medio natural y al medio técnico ( SANTOS Y SILVEIRA, 2001).

Aceleración de la urbanización, y del crecimiento numérico y espacial de las ciudades.

- Fragmentación y nueva especialización regional a escala internacional

- $\quad$ Perdida del papel de la cultura en la diferenciación de los espacios

- Desarraigo de cada sociedad de su espacio geográfico: des territorializacion, y perdida de memoria espacial

Des lugarizacion o formación de los no lugares : la perdida de la identidad cultural de los espacios, paisajes, regiones y lugares, o sea de la coherencia, la singularidad y la armonía.

- La disminución del numero de lugares significativos y de paisajes diferenciados

La colonización portuguesa encontró a culturas amazónicas poco desarrollada técnicamente, caracterizadas por un estilo de vida en los que no existía ningún vestigio de ordenación urbana, y en la que los indígenas se organizaban principalmente bajo la forma de tribus de agricultores semi nómadas, practicando una agricultura itinerante.

El proceso de modernización, y de ocupación espacial y territorial por los representantes de culturas foráneas, en el caso de la Amazonia, comenzó cuando se implanto una economía extractiva.. Durante 
siglos la colecta y el extrativismo de la castaña de para, la borracha, el guarana, las esencias vegetales, la madera, y la caza de pesca de subsistencia conducian a un predominio de un régimen natural en la cuenca. Sin embargo la organización territorial de la modernidad en la Amazonia, se fue llevando a cabo lentamente con la fundación de una red de pequeños pueblos (NÚÑEZ JIMÉNEZ, 1999). En 1852 Manaus fue elevada al rango de capital de provincia, y al final del siglo XIX paso a ser un centro importante de comercio de borracha, ocupando así un papel preponderante como polo en la organización espacial del territorio amazónico del Brasil.

Es a partir de 1970 en que se produce el cambio significativo del modelo de desarrollo en la Amazonia Brasileña. Hasta esa época los bosques estaban muy poco modificados por la acción de las actividades humanas. Los elementos básicos del nuevo modelo desarrollista fueron los siguientes: aplicación de estímulos fiscales de diferente naturaleza, y la creación de facilidades de penetración con la apertura de una red de carreteras (tales como la Trans amazónica, Cuiaba- Santarem, Belem - Brasilia, Cuiaba - Porto Velho, Porto Velho - Manaus entre otras) construidas para servir como ejes de colonización tanto para el Centro Oeste como para la región amazónica, acompañado de tentativas de ocupación de todo el territorio nacional, que desencadenaron una vigorosa migración del Sur, el Sudeste y el Nordeste para la región amazónica.

Progresivamente los bosques dieron lugar a cultivos de ciclo corto, tales como arroz, frijoles, maíz y yuca. Después daban lugar a pastos improductos, resultado de la perdida de la fertilidad de los terrenos. De este modo, el bosque amazónico se ha ido reduciendo en un $20 \%$ en 30 anos.

Otro elemento fundamental en la estrategia desarrollista fue la creación de la Zona Franca y el Distrito Industrial de Manaus. La idea era de convertir a Manaus en un polo de crecimiento. En la Zona Franca de Manaus se establecieron las sedes de establecimientos de industrias de bienes de consumo duraderos de empresas nacionales y multinacionales, con sedes en el exterior o en el sudeste del país. Esas industrias trabajan con piezas importadas de otras regiones del país o del exterior. Son más que todo montadoras de productos que se venden fuera de la región donde son producidos. Es por eso que se consideran como polos de crecimiento artificiales., nacidos sobre la base de una planificación y de intervenciones inducidas por el Estado en consonancia con empresas y agentes económicos. La tentativa era convertir a la Amazonia en una región polarizada, que sobre la base de un centro polo se estimulase el crecimiento económico de sus áreas de influencia.

Sin embargo, la investida desarrollista en la Amazonia en las ultimas décadas ha sido un gran fracaso (SANCHES ROSS, 2000).

Por una parte, mas que todo se creo un verdadero "colonialismo interno" (Scarlato, 2000), en el que la base del poder, estaba en el sur y en el exterior del país. Por otra parte, se hizo contradictoria la producción de bienes de consumo con piezas traídas de fuera de la región, en el que se estimulo un proceso de desintegración regional, que no tenia nada que ver con su función de acuerdo al potencial natural.

Esa transformación se ha realizado sobre la base de convertir a la Amazonia en un paraíso de los latifundistas. El origen de los latifundios esta en la "técnica de la procuración", que consiste en que el latifundista se consigue un procurador de un cierto número de personas que atestiguan que esa tierra le fue entregada a sus antepasados por la Corona. De ese modo las tierras de las naciones indígenas han sido saqueadas y la población nativa diezmada por el etnocidio y el genocidio (NÚÑEZ JIMÉNEZ, op.cit.). La población indígena del Brasil que se estimaba en 5 millones en la Época del Descubrimiento, 
hoy cuenta apenas con 220 mil indios. (de Oliveira, 2000) Actualmente las áreas reinvidicadas por las naciones indígenas no alcanzan ni el $10 \%$, cuando al principio de la llegada de los europeos ellos eran dueños de todo el territorio actual del país.

Por otra parte, las consecuencias ecológicas y ambientales de ese modelo antiambiental pueden caracterizarse por lo siguiente:

\section{- $\quad$ Alteración de la red hidrográfica \\ - Destrucción de la biodiversidad \\ - Degradación de los paisajes naturales,} con la destrucción de la capacidad de intercambio de substancias, y la perdida de fertilidad de los suelos.

- Cambios climáticos

- Incremento significativo de las plagas y enfermedades.

De tal manera, las características de la desarticulación espacial en la Amazonia brasileña han sido las siguientes:

- La implantación de un modelo desarrollista imitativo de experiencias foráneas, basado en el crecimiento económico a ultranza, socialmente no equitativo y ambientalmente explotador fundamentalmente a partir de 1960 a través de la apropiación capitalista de la frontera.

- Ampliación de la frontera agrícola: formación de grandes potreros homogéneos, poco productivos, actualmente ampliación de la faja de la soya

- Crecimiento urbano excesivo: creación de una red urbana bajo la forma de una malla programada; creación de nuevas ciudades planificadas,

- Sistema viario basada en el transporte rodoviario (de carreteras)

- Amplia significación de actividades extractivas

- Intensa transformación del régimen de los paisajes naturales: creación de inmensos embalses, deforestación, contaminación fluvial
Industrialización ficticia mediante la creación de la Zona Franca de Manaus

Proceso de inserción a las redes nacionales y mundiales espacialmente desiguales, y dependientes de centros situados fuera de la región.

\section{LA DESARTICULACIÓN DE LOS PAISAJES DE LA AMAZONIA}

La propia transformación y desarticulación de los paisajes naturales, se ha manifestado en un proceso continuo de alteración de los paisajes naturales de la región y de los lugares amazónicos. Este proceso de formación de los paisajes amazónicos se puede distinguir en tres etapas principales:

La etapa del paisaje indígena: es marcado por los tiempos lentos de la naturaleza, comandado por las acciones humanas puntuales y de impacto reducido de los grupos indígenas. La presencia humana buscaba adaptarse a los sistemas naturales. Predominaba así el inmenso telón verde, de la inmensidad del bosque, con matices enmarcados por el río, las sabanas, los cerros y las escarpas de los tabuleiros.

La etapa del paisaje del uso extractivo de la naturaleza: Las lógicas y los tiempos de las influencias humanas externas van incorporándose a la naturaleza original. Con la demanda del exterior se va formando la zona económica amazónica en el que predomina un medio técnico pre mecanizado. La incorporación de la influencia industrial y de la maquinaria, a través de la construcción de puertos y grandes ciudades es solo puntual (principalmente Manaus, y Belem). Si bien predomina el verde del bosque, y las formas naturales, puntualmente se van erigiendo pequeños pueblos y campos agrícolas en sus entornos. Aquí los símbolos de la civilización brasileña, con la presencia clara de los símbolos patrios nacionales y en particular 
de la iglesia católica, paralelo a algunos símbolos innatos de la nueva colonización de la borracha, cuya icono mas singular es el Teatro Amazonas de Manaus., van dominando cada vez mas y mas.

- Laetapadelaintegración:Paramediados del siglo XX Amazonia queda en la periferia del proceso de integración nacional. La industrialización y la integración del territorio y del mercado es tardía. La heterogeneidad y singularidad del espacio regional es relegada a un segundo plano, en un intento por dominar la naturaleza, e imponer un modelo desarrollista no acorde con las peculiaridades regionales. Grandes extensiones de pastos que van sustituyendo al bosque, van conformando un paisaje artificialmente homogéneo, no de color verde, sino de amarillo claro a verdoso, en lugares con puntos rojos en los que aflora el suelo latolosico. Las grandes, medianas y pequeñas urbes urbanas, al lado de agrovillas desorganizadas, rompen y desfiguran el paisaje original.. La ideología del consumo, del crecimiento económico y de la planificación, se manifiesta mediante una sensible alteración de los paisajes amazónicos. Amazonia se incorpora al tiempo rápido y hegemónico de todo el Brasil, con sus símbolos, sus colores, sus cadencias. La ocupación de esta gran área periférica con producciones modernas, se realiza bajo una significativa ruptura, que se manifiesta en la disociación de la producción, en la desarticulación paisajística y el colapso ambiental. Las diferencias naturales se esconden tras el velo de las diferencias sociales.

En este proceso, los paisajes se hacen menos auténticos, menos diferenciados, menos singulares, menos armónicos, menos coherentes. De tal manera disminuye sensiblemente la identidad de los paisajes. Van a predominar entonces los siguientes procesos de alteración de los paisajes:

- Des enraizamiento: manifestado en la creación de paisajes que responden a otros símbolos, a otras culturas, a otras raíces y que responden a las fuerzas políticas, ideológicas o religiosas dominantes: son los símbolos del Estado Brasileño o de la Iglesia Católica, que poco a poco se han ido implantando y llenando de geo símbolos, sean oficiales, o religiosos el espacio amazónico.

- Subtopia o banalizacion,: consiste en la formación de paisajes de la periferia, en los que predomina la perdida de la calidad visual y estética, en la que los impactos negativos sobre los mecanismos sensoriales se hacen predominantes. Los paisajes se homogenizan, se afean, y acompañan a todo el mecanismo de destrucción de los factores naturales que garantizan su sustentabilidad.

- Favelizacion, representan la expresión máxima de la banalizacion, acompañadas por condiciones infrahumanas de existencia

- Mestizaje, implica el uso de las formas tradicionales del paisaje, en combinación con otras formas en el paisaje antropizado, pero desprovistas de su contexto original. Son casas de los grupos indígenas, o incluso pequeños asentamientos en un paisaje de sabana humanizada. Incluye también el mestizaje con las culturas sincréticas afro brasileñas, propios de los mercados.

- Modernización e hiper modernización, es la incorporación de elementos provenientes de las formas de explotación moderna, tales como industrias y otras edificaciones, nuevas urbanizaciones con edificios y viviendas modernas, las carreteras, los anuncios

- Museificacion y disneyficacion, representan generalmente formas de los usos turísticos, en los que se reconstruyen los paisajes originales desde una perspectiva de su estenografía, o su uso como espectáculo. Son los parques temáticos, tales como los "Parrot Jungla ", aldeas indígenas, o los museos en los que se mitifican y repiten construcciones e iconos originales.

Paralelo a este proceso de desarticulación de los paisajes, los lugares, van perdiendo su originalidad, se desarticulan, se maquillan con los elementos cosméticos 
de la modernidad. Disminuyen los de lugares significativos. Ellos que representaban la relación topofilica intensa entre los grupos indígenas, y después entre los nuevos pobladores amazónicos (seringueiros y ribereños) con su medio afectivo, van tornándose en algo propio de poblaciones y culturas foráneas. La uniformizacion de lugares se debe a que ellos pasan a ser creados para personas con necesidades y gustos supuestamente uniformes de acuerdo a los valores de masa. Esos son los valores de la triple ideología del consumo, el crecimiento económico y la planificación inducida.

Se va perdiendo así la relación sociedad - entorno. La gente deja de entender el funcionamiento del sistema natural, y deja a un lado la cultura de la adaptación, para abrazar una cultura de la dominación. Pasan entonces a predominar entre la población amazónica las experiencias inauténticas. que conducen a la perdida de las relaciones afectivas de los seres humanos con su entorno, y que son el fundamento en la formación de los lugares y en los sentidos de territorialidad. Ello se manifiesta en que es cada vez mas dificil la formación de un sentido profundo de lugar. La ausencia del sentido del lugar, conduce a una falta de preocupación con las expresiones simbólicas de los paisajes. La gente va perdiendo su identificación con el entorno natural, va perdiendo su relación de afecto, va disminuyendo la capacidad de la formación de un saber empírico e innato, y del conocimiento del espacio que los rodea, y va dejando a un lado e incluso relegando las imágenes del medio del cual nació. Las gentes se van identificando entonces, con un medio artificial, antropizado, que se deteriora rápidamente y que pierde su fertilidad natural, y va dejando a un lado el conocimiento empírico, y las experiencias culturales que le permiten justamente adaptarse al entorno. Todo eso se manifiesta en un empobrecimiento de las fuerzas que aseguran la existencia de una cultura original.
De tal manera, la desarticulación de los paisajes en la región amazónica se caracteriza por los siguientes rasgos:

- Procesos de desarticulación: desenraizamiento, banalizacion y subtopia, favelizacion, mestizaje, hiper modernización, Museificacion y disneyficacion.

- La cada vez menos posible creación autentica de paisajes y lugares

- La formación cada vez mas difícil de un sentido profundo de lugar: la ausencia del sentido del lugar, la no preocupación con las expresiones simbólicas de los paisajes

- La disminución del numero de lugares significativos y de paisajes diferenciados

- La uniformizacion de los productos y los lugares que pasan a ser creados para personas con necesidades y gustos supuestamente uniformes de acuerdo a los valores de masa

- El crecimiento continuo de las experiencias inauténticas.

De tal manera, los nuevos paisajes culturales que se han creado en la Amazonia, no corresponden por completo con su fundamento natural y con las formas originales que lograron las culturas amazónicas mediante la creación de formas y nexos adaptativos, y con aquellas propiedades que deben garantizar la sostenibilidad de la naturaleza, y de por si la propia sostenibilidad económica y cultural del proceso de desarrollo de la región como un todo.

\section{A MANERA DE CONSIDERACIONES FINALES: EL FUTURO DE LA AMAZONIA}

De tal manera, la desarticulación de los paisajes amazónicos esta provocando:

- La disminución de la cohesión hacia adentro de las sociedades,

El aumento de la vulnerabilidad ante la 
influencia de los desarticuladores externos.

- La destrucción del soporte y el fundamento de la formación de las identidades - El socave de la memoria territorial e histórica de los pueblos.

- La desarticulación de un producto cultural de los pueblos amazónicos, al desarraigar los ambientes simbólicos, creados por la acción humana que les confiere significado y forma a la Naturaleza y al ambiente, a partir de un conjunto de valores y creencias.

- La des estructuración de de las fuentes de los imaginarios colectivos, al desarticular las imágenes de sus pobladores.

- La alteración de las relaciones afectivas de los seres humanos con su entorno, y fundamento en la formación del concepto de lugar y de territorialidad

- La desaparición de la base en que se sustenta las culturas amazónicas

Se impone entonces la necesidad de que las poblaciones amazónicas tengan entonces que desarrollar una verdadera cultura de resistencia. Esa cultura de la resistencia, necesita como elemento fundamental de una capacidad de restaurar, rehabilitar y recomponer sus paisajes, sus lugares, y sus nexos y configuraciones regionales. Solo asi es posible salvar las culturas amazónicas.

La historia de la ocupación y destrucción de los paisajes de la Amazonia, ha sido una historia también de resistencia. Los movimientos sociales rurales también han llegado a la Amazonia. En Acre, los trabajadores rurales han organizado sindicatos que han luchado contra la deforestación, por la conservación de sus estilos de vida y de adaptación ala naturaleza, y también contra los latifundistas. Fueron liderados por Wilson Pinheiro y Chico Mendes, ambos asesinados en la década del 80 del siglo XX. Ellos y sus seguidores han luchado por la implantación de reservas extractivistas, como una forma de preservación del bosque y de implantación de la reforma agraria.

Los pueblos indigenas han estado también presentes en los frentes de lucha para la preservación de sus tierras. Son pueblos que tienen su sobre vivencia amenazada por las constantes invasiones de sus tierras por latifundistas, garimpeiros y empresas transnacionales.

Hay numerosos ejemplos en las universidades, en las comunidades,. en gobiernos municipales, e incluso estaduales, tal y como lo es el esfuerzo del Gobierno de la Floresta de Acre, de elaborar y ejecutar proyectos dirigidos a recuperar los paisajes amazónicos, como base para la construcción de un nuevo paradigma de explotación de los recursos naturales y de recuperación de la cultura de los pueblos amazónicos.

Como parte de esa cultura de la resistencia se imponen dos tareas básicas: la recuperación de los paisajes y la educación paisajística. En el ámbito de la recuperación y rehabilitación ambiental, se impone el uso de las técnicas del análisis paisajístico como elemento básico dentro del nuevo paradigma ambiental (MATEO, DA SILVA, AGOSTINHO, 2004). Al mismo tiempo, como instrumento educativo, la lectura geográfica del territorio haciendo uso del paisaje, permite aprehender los reflejos geográficos, que constituyen los elementos básicos de la cultura geográfica, Revelar los contenidos del patrimonio natural y cultural que está presente en los paisajes, a través de una lectura experta, constituye un ejercicio de cultura geográfica, ambiental y territorial. Así, un proceso de educación integral y ambiental, basada en el paisaje como elemento tangible, puede constituir una tarea de primer orden en la salvación y consolidación de las culturas amazónicas. En ambos casos se trata de articular el saber experto con el saber, y la experiencia original de los pueblos amazónicos, para lograr una verdadera integración y potenciación de las experiencias de todos los interesados en salvar a la Amazonia. ${ }^{2}$

2 Para la construcción de una teoria sobre la 


\section{BIBLIOGRAFÍA}

ÁNGEL MAYA, A.- La fragilidad ambiental de la cultura., Editorial de la Universidad Nacional, Bogotá, 1995, 127 pgs.

BARBOSA, Y. M.- O despertar do turismo. Um olhar critico sobre os nao lugares; Editora Aleph,Sao Paulo, Brasil, 2001,101 pgs.

BUENO CONTI, J., S. A. FURLAN.- O clima, os solos e a biota; En: Geografia do Brasil, Editora da Universidade de Sao Paulo; Sao Paulo, 2000, pp. $167-208$

DE OLIVEIRA, A. U.- A mundializacao do capitalismo e a Geopolitica mundial no fim de seculo XX., En: Geografia do Brasil, Editora da Universidade de Sao Paulo; Sao Paulo, 2000, pp. $239-288$

FERREIRA, L. F.- Iluminando o lugar: tres abordagens (Relph, Buttimer e Harvey): Boletim Goiano de Geografia; Goiania, Brasil, v.22., No.1, 2002, pp.43 - 72

NUÑEZ JIMENEZ, A.- De canoa do Amazonas ao Caribe; IPAAM, Manaus, 1999, 298 pgs.

MATEO, J.- Paisajes Culturales., Notas del curso de post grado., Universidad Nacional de Colombia, Sede Manizales, 2003, 278 pgs.

MATEO, J., DA SILVA, E., N. AGOSTINHO.Geoecologia das Paisagems; Editora da Universidade Federal do Ceara, Fortqleza,

rehabilitacion de los paisajes culturales en America Latina, , seria interesante llevar a cabo un análisis comparativo con la manera en que se han transformado y construido los paisajes en la Region del Caribe. Aparte de las diferencias, tal análisis seria provechoso, en tanto las posibles interrelaciones que han existido entre las culturas de ambas regiones, y para visualizar como dos regiones en diferente estado evolutivo (la Amazónica en un estadio más inicial de trasformación, la Caribeña en un eswtado mas avanzado) han respondido a los impactos de la globalización. En este sentido, hay dos trabajos sobre las transformaciones de la region caribeña que pueden servir de referencial: el trabajo Paisajes naturales y culturales de Cuba: cambios ocurridos en los últimos 50 años, presentado por J. Mateo en el 9o. Encuentro de Geografos de America Latina, celebrado en Merida, Mexico en el 2003, y el trabajo de J.Seguinot "La Globalización del Paisaje de Puerto Rico , publicado por el Instituto de Estudios Del Caribe de San Juan en 1996.
2004, 345 pgs.

SANCHES ROSS, J. L.- Os fundamentos da Geografia da Naturaeza; En: Geografia do Brasil, Editora da Universidade de Sao Paulo; Sao Pauloo, 2000, pp. $13-66$.

SANTOS, M.- Espaco e Metodo, Editora Nobel, Sao Paulo, 1985, 237 pgs.

SANTOS, M.- Metamorfoses do espaco habitado; Hucitec; Sao Paulo, 1994,124 pgs

SANTOS, M.- A natureza do espaco. Técnica e tempo. Razao e emocao., Editora Hucitec, Sao Paulo, 1996, 308 pgs.

SANTOS, M., y M. L. SILVEIRA.- O Brasil: territorio e sociedade no inicio do seculo XXI; Editora Record, Rio de Janeiro, 2001, 474 pgs.

SCARLATO, F. C.- O espaco industrial brasileiro; Populacao e urbanizacao brasileira. En: Geografia do Brasil, Editora da Universidade de Sao Paulo; Sao Paulo, 2000, pp. 327 - 464. SEGUINOT, J.- Globalization of the landscape or Puerto Rico; In: Globalization in America: a geographical approach: Instituto de Estudios del Caribe, San Juan,.P.R., 1996, pp. $79-92$. 